\title{
Nuevas miradas del cine. El cine documental en primera persona
}

Pablo Piedras: El cine documental en primera persona. Buenos Aires: Paidós, $20 \mathrm{I} 4$. ISBN 978950 I27 5872

\section{Lidia Graciela Acuña}

Facultad de Humanidades y Ciencias, Universidad Nacional del Litoral

En las producciones del cine en Argentina, hacia el año 2000 se desarrollaron distintas formas del documental en primera persona. Desde fines de siglo $\mathrm{xx}$, en la literatura y otras expresiones, lo autobiográfico irrumpió como una tendencia relevante. En el país, a partir del año 2000 , se concretó la renovación de la expresión documental en general $y$ en particular el desarrollo del filme en primera persona. El marco sociohistórico argentino enmarcó esta tendencia con filmes sobre la memoria, identidad e hijos, entre otros.

En esta tendencia se concretaron gran variedad de obras por un lado y, por otro, se creó interés en análisis y estudio sobre las producciones. En este sentido, estudiantes e investigadores del campo del cine carecían de material apropiado y actualizado en el país. El libro de Piedras vino a cubrir esta ausencia brindando una gran contribución al análisis de la problemática. El libro es una reelaboración de su tesis doctoral que focaliza en el cine documental argentino, lo cual lo enriquece. El autor aborda una categoría más específica dentro del panorama del nuevo cine argentino. En el contexto de cambios de la evolución del cine, Piedras aporta al estudio sobre la conceptualización del yo autoral, la historia y memoria y la representación del otro en el documental argentino de los últimos años. Deconstruye el desarrollo de la primera persona del director o la directora en las narrativas 
documentales como exponentes de subjetividad o "documental performativo", como ocurre en filmes como: Los rubios, $M$, Papa Iván y Yo no séque me han hecho tus ojos, para mencionar sólo algunos de los documentales que aquí se analizan en detalle. El prólogo enfatiza en que las categorías de Bill Nichols, ya clásicas e ineludibles para este tipo de estudios, son limitadas para todo lo acontecido en Argentina, donde el documental hizo una nueva irrupción en la poscrisis del 2000, cuando las modalidades de los documentalistas argentinos encontraron un lugar distinto y gran variedad. Piedras destaca la película Papá Iván (María Inés Roqué, 200o) para ejemplificar la narrativa en primera persona a partir del comienzo del nuevo siglo como una reconstrucción de la memoria.

El primer capítulo describe la evolución y los antecedentes del Nuevo Cine Argentino que desarrollaron posibilidad para este género en su modalidad subjetiva. Piedras marca el desarrollo del cine argentino como vinculado a las producciones de la generación del ' 60 de nuestro país, que aportaron particularidades del nuestro cine.

El segundo capítulo se enfoca en las inflexiones del yo en el documental contemporáneo. Piedras cree que la nueva generación de directores influyentes en Argentina (Ana Poliak, Martín Rejtman, entre otros), que fue formada en su mayor parte en las escuelas de cine, provoca este cambio al yo autoral gracias a su conocimiento del cine moderno internacional. Desde el cinéma verité de Francia al cine de los Estados Unidos como modelos influyentes en el documental participativo que, por las técnicas de montaje contrapuntístico, materiales de archivo públicos y privados, las entrevistas y escrituras íntimas (diarios, cartas y autorretratos), imbrican la historia colectiva y la personal. Además, aborda los factores que explican los cambios históricos y culturales en el ámbito cinematográfico y las nuevas tecnologías que permiten una relación más versátil con los medios audiovisuales y de producción. Desarrolla la subjetividad en el filme como la figuración del cuerpo en un tipo de documental más personal, donde los medios de producción son «transparentes».

El autor, en el tercer capítulo, hace una comparación entre el documental y los abordajes sobre la literatura occidental en donde la primera persona es autobiográfica. Presenta diferencias como el absolutamente personal del autor, como, por ejemplo, la mirada de una hija de padres capturados durante la dictadura es muy distinta en Los Rubios (Albertina Carri, 2003) que en Papa Iván (María Inés Roqué, 2000), pero estos filmes, bajo la mirada de Piedras, pueden ser considerados como una representación desde una voz privilegiada sobre lo acontecido en esos años. Visto desde la óptica 
que propone Piedras, lo que importa es la impresión de proyectar una verdad colectiva social e histórica.

En el cuarto capítulo continúa con un desarrollo más filosófico-histórico, que se prolonga en los últimos capítulos con el análisis de los temas de la historia y la memoria. Piedras plantea el problema de la autenticidad; en este sentido, la verdad completa no siempre tiene que ver con el entendimiento e incluso con la confianza del espectador.

El quinto capítulo trata de la representación de los otros. Piedras añade a la discusión de la ética en la etnografía la precisión de que los documentales subjetivos, anclados en tiempos posmodernos, no pueden hacer un gran relato para proteger a todos los protagonistas, como Nichols define la ética, cuando es una historia personal con experiencias propias del cineasta.

Así, queda planteado el cine documental en primera persona, como un nuevo $y$ necesario aporte para la actualización de los estudios en la narrativa documental, cambia la percepción habitual según la cual los documentales objetivos se acercan a la verdad de una manera más ética y cabal que los subjetivos. Al valorizar el enfoque en la identidad del cineasta inscribe el análisis en el contexto contemporáneo y propone apreciar la experiencia singular en un marco en el que, en las artes en general, la conciencia colectiva es cada vez más elusiva pero aprehensible desde la más absoluta singularidad.

Piedras nos brinda aportes teóricos y herramientas para un análisis renovado y necesario de los documentales subjetivos. Además, ofrece un libro actualizado con corpus documental de filmes argentinos que facilita a los estudiantes de cine y artes el abordaje del cine documental actual abriendo nuevas líneas de investigación y desarrollo. Sus aportes son elementos para el desarrollo de estudios comparados en la variedad de las producciones subjetivas. 
